\title{
Effect of heating temperature on quality of bio-briquette empty fruit bunch fiber
}

\author{
Nofriady Handra', Anwar Kasim², Gunawarman ${ }^{3}$, Santosa $^{4}$ \\ ${ }^{1}$ Mechanical Engineering Department, Institut Teknologi Padang, Indonesia \\ ${ }^{2,4}$ Faculty of Industrial Agriculture Technology, Andalas University, Indonesia \\ ${ }^{3}$ Mechanical Engineering Department, Andalas University, Indonesia
}

\begin{tabular}{l} 
Article Info \\
\hline Article history: \\
Received Feb 29, 202 \\
Revised Apr 23, 2020 \\
Accepted May 2, 202 \\
\hline Keywords: \\
Bio-briquette \\
Calorific value \\
Empty fruit bunch \\
Fiber \\
Temperature
\end{tabular}

\section{Corresponding Author:}

Anwar Kasim,

Faculty of Industrial Agriculture Technology,

Andalas University, Padang West Sumatera, Indonesia

Email: anwar_ks@yahoo.com

\begin{abstract}
Empty Fruit Bunches (EFB) are one of the palm oil industry wastes, which are quite plentiful and currently unused optimally. Biomass is one of the renewable energy resources which has important roles in the world. The bio-briquettes are manufactured through densification of waste biomass by implementing certain processes. This research aimed to obtain variations in the mold temperature at $150{ }^{\circ} \mathrm{C}, 200{ }^{\circ} \mathrm{C}$, and $250{ }^{\circ} \mathrm{C}$ to the calorific value and toughness of the briquette material. The toughness was tested using ASTM D 440-86 R02 standard. Arduino program was used for setting the heating resistance time of the mold, which was 20 minutes and the thermal controller was used to adjust the temperature variation. The average mold pressure was 58 Psi. The highest heating value was obtained at a mold temperature of 250 ${ }^{\circ} \mathrm{C}$ with a value of $5256 \mathrm{cal} / \mathrm{g}$, and the lowest was resulted at a temperature of $150{ }^{\circ} \mathrm{C}(4117 \mathrm{cal} / \mathrm{g})$. Meanwhile, the briquette toughness test at $200{ }^{\circ} \mathrm{C}$ mold temperature indicated good data results in which the average loss of fiber particles was only $4.17 \%$, this was because the adhesion between particles by lignin and cellulose in the fiber functions optimally at this temperature so that the resistance of briquettes went through minor damage.
\end{abstract}

This is an open access article under the CC BY-SA license.

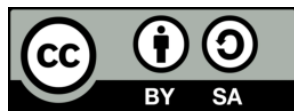

\section{INTRODUCTION}

Energy has emerged as an important issue recently in the world affecting the economic development along with the growth of population, fuel emission problems, and not to mention depletion of oil reserves. The relentlessly increasing consumption of fossil energy has triggered the crisis of fuel. The idea of limiting the fuel oil and gas procurement encourages the renewable fuel development. Indonesia, as an agriculture country, has abundant stock of agriculture products which can be used as one of the renewable energy sources, for example biomass. From about 50,000 megawatts, there are only 320 megawatts of biomass energy that have been used; it is just about $0.64 \%$ from the total biomass that Indonesia [1].Energy from biomass is considered an ideal renewable energy source since it has some benefits such as lower sulfur, $\mathrm{CO}$ neutral emission, and abundantly available in the form of agriculture product wastes. Therefore, this renewable energy has been well-known as one of the potential alternative energies. Bioenergy which is produced from biomass becomes a promising, limitless, and sustainable energy source. In addition, it may help minimize the increasing problems related to environment, economic, and technology because of the fossil fuel depletion [2]. The motivation of utilizing bioenergy as the fossil energy substitution either in 
heating or electricity generation field is affected by the consideration of the increasing environmental and energy dependency. Since several decades ago, the biomass development has become a crucial issue. Even, it will keep being interesting for the future since this energy is clean, can be renewable, as well as containing carbon-neutral properties. It needs to find the solutions to tackle down this issue. One of which is utilizing an alternative energy, especially the renewable one. The move from oil energy source to the renewable one which is plenty available in Indonesia can lower the dependence level on petroleum. Biomass serves as one of the sources of renewable energy. Biomass is produced from photosynthesis of plants and the derivatives of plants. Biomass promises more value since it is actually a green energy. Biomass consumption does not disrupt the environment since it can be renewable and $\mathrm{CO}$ combustion can be reabsorbed by plant, thus, in other words, it is zero emission. In general, biomass waste can be gained from plantation industry, agricultural products, or industry which use raw materials coming from forests [2]. Biomass briquettes can be uses as a biofuel substitute for coal and charcoal. They are commonly used in the developing countries, in which cooking fuels are not easily found, to heat industrial boilers in generating electricity from steam. In order to produce the heat for the boiler, briquettes with coal are burned. Interestingly, briquettes had been used since before the recorded era. They are made of agricultural waste and can replace the fossil fuel, e.g. oil and coal, and can be utilized to heat the boiler for the manufacturing plants. Briquettes serve as a renewable energy source since it will toxic the atmosphere with fossil carbon [3].

Several previous studies have examined the use of briquettes in several ways to alleviate the aforementioned problem. One of the technologies used is a densification as it improves the handling characteristics of raw materials as well as enhances the volumetric calorific value of the biomass. Previous studies on briquette technology have been done [4, 5]. They reviewed the effect of raw materials, temperature, binders, and pressure. Some also reviewed the combustion properties of densified palm biomass, e.g. moisture and ash content, and calorific value. Burning rate was discussed in certain sections [6]. One of the agricultural products which is traded in the domestic market as well as exported is palm oil. The production of palm oil leaves palm Empty Fruit Bunch (EFB), which is considered wastes and not re-processed. These wastes lead to an issue for space and transportation of disposal which eventually bears extra cost for the industry. In disposal, empty fruit bunches is commonly burned in which this process leads another environmental problem such as air pollution and odor. Uncontrolled empty fruit bunches disposal to land leads to large quantity of biomass empty fruit bunches piles in palm groves in which eventually ends to anaerobic decomposition process. Therefore, considering some potential issues such as pollution, empty fruit bunches waste should be managed properly to require the use of biomass renewable energy and produce heat energy for public. A factor that affecting the process of making briquette is adhesive level and waste biomass briquette optimization. The former increases the briquette calorific value as can be found in the element carbon addition. Although, excessive adhesive level will lead to the burning briquette since the pores will be filled with adhesive briquettes and make the briquettes too dense. Not to mention, the adhesive level is affected by the waste biomass type. To be safely used at home, the burning briquette smoke must be reduced. Therefore, it needs to optimize the adhesive level of waste biomass briquette that will be used as fuel. The idea of this research is to see the amount of agricultural industrial wastes that are not utilized properly in the community. Among these wastes is empty fruit bunches. Empty Fruit Bunch waste can actually be processed into solid fuels in the form of briquettes. Biomass waste can be directly used as fuel, converted first into charcoal or pressed into briquettes first. The purpose of pressing is to obtain a better combustion quality and ease of use and handling. Biomass cannot be directly used as fuel because of its low physical properties such as: small energy density, and problems with its handling, storage and transportation, so diversification needs to be done including products such as briquettes or pellets [7]. Converting biomass into better forms can improve its quality as a fuel such as increased fuel power, combustion efficiency, a more uniform shape, drier products and greater mass density. Many previous researchers have discussed the problem of making briquettes from various materials such as charcoal briquettes, Barks wood, Wood chips, Paddy straw, Sawdust briquette, Palm husk, etc. Some of these briquettes use adhesives as reinforcement in the mixture. Meanwhile, in this study biomass briquettes were made without adhesives by the hot temperature regulation method in the mold, so that the ideal temperature is able to produce briquettes with maximum heating value.

The use of EFB as an energy source in the form of briquettes, in addition to providing financial benefits, will also help in environmental preservation. The EFB can be made charcoal by a relatively simple process. For the purpose of utilization as charcoal, According to Guritno, needs to be further processed into charcoal briquettes to increase its density and provide a regular shape. In addition, heat energy from EFB of $18,79 \mathrm{~kJ} / \mathrm{kg}$ is very potential to be used as an alternative energy source. The use of briquettes as fuel can save time and costs because briquettes have a relatively high calorific value [8]. The novelty aspect of this research is focused on the manufacture of briquettes without adhesives by determining variations in the appropriate heating temperature so as to be able to get good briquette properties. Some studies that are 
relevant and support this research include Hasan et al. The binderless briquettes are possible to be formed when continuous heating is applied within the temperature range of $150{ }^{\circ} \mathrm{C}$ to $210{ }^{\circ} \mathrm{C}$. This means lignin that serves as a natural binder for the briquette has been produced due to heating process [9]. Briquette making can be done by the hot print method. This method uses raw material for biomass that has not yet been carbonized. The purpose of heating is to activate natural adhesives (lignin \& hemicellullose) found in the raw material. Natural adhesives contained in biomass can be activated by increasing the temperature. Lignin has amorphous thermoplastic properties that can be activated through low compacting pressures and temperatures around $60{ }^{\circ} \mathrm{C}$. Activation of natural adhesives with high compacting pressure and increasing temperatures can produce briquettes and pellets that have high durability [10]. This research aimed to obtain variations in the mold temperature at $150{ }^{\circ} \mathrm{C}, 200{ }^{\circ} \mathrm{C}$, and $250{ }^{\circ} \mathrm{C}$ to the calorific value and toughness of the briquette material on binderless briquette. In this study, briquettes were made using the hot mold method without binder in the hope of eliminating water-based binder in the manufacture of briquettes. The purpose of heating is to heat the fiber raw material so that the lignin content (one of the substances contained in the fiber) is able to melt and harden again at room temperature, so that the thermoplastic properties contained in the raw material are used as binder in making briquettes.

\section{RESEARCH METHOD}

\subsection{Raw materials}

The Empty Fruit Bunch fibers and briquettes were acquired from TAL Ltd at Kuansing Taluak Kuantan, Riau - Indonesia. It used the fresh condition of fiber and empty fruit bunches. Waste of empty fruit bunches was used in this study as shown in Figure 1.

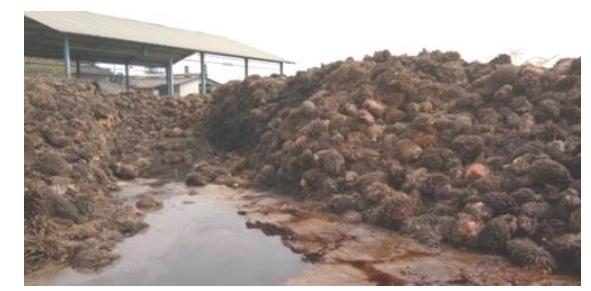

Figure 1. Waste of Empty Fruit Bunch (EFB)

Figure 2a shows empty fruit bunches was directly dried under the sun. Fiber enumeration was manually done to obtain the fiber fineness size, i.e. 1-3 mm. Fiber which was chopped produced both fiber and powder in various lengths, as can be seen in Figure 2b. Oxygen Bomb Calorimeter (OBC) Type Ignition Unit 2901EE was used to determine the heating values of both empty fruit bunches fiber and briquette. Meanwhile, to obtain the fiber and adhesive weight on each sample, digital scale with KW $0600378500 \mathrm{~g} \mathrm{x}$ $0.01 \mathrm{~g}$ was used.

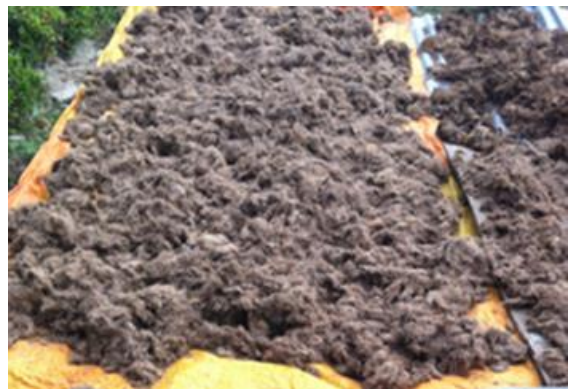

(a)

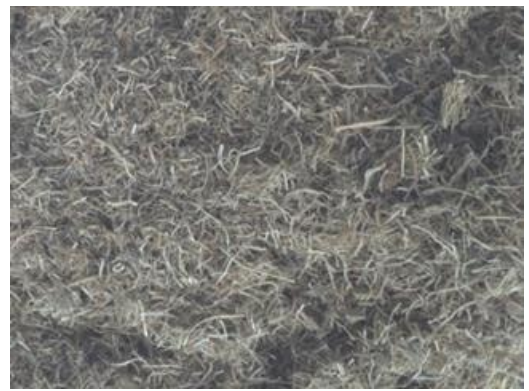

(b)

Figure 2. (a). Empty Fruit Bunch of dried under the open sun drying, (b). empty fruit bunches fiber after cutting 


\subsection{Mold}

The process of this research was to use one unit of briquette molding equipment by giving a heating system to the mold cylinder as shown in Figure 3a. Variation of heat temperature was given at $150{ }^{\circ} \mathrm{C}, 200$ ${ }^{\circ} \mathrm{C}$, and $250^{\circ} \mathrm{C}$ with a holding time of 20 minutes for each temperature. During the holding time, the heated fiber will undergo a compaction process both physically and chemically. Densification temperature is an important factor that could affect the combustion properties especially calorific value. When the operating temperature is relatively high, the calorific value of the densified products increases if compared to the value of the raw materials. The tests given in the sample are toughness and heat value, ash and charcoal content. Cattaneo mentioned that briquette is compressing the materials into small logs with a diameter of between 30 $\mathrm{mm}$ and $100 \mathrm{~mm}$ and of any length depending on the technology used, either screw or piston compression [11]. For producing high-quality briquette, several characteristics such as strength and durability must be considered [12]. In this study, mold briquette was used as the support molding to make briquettes which have a predetermined classification. The mold was processed by pressing a part of suppressant resulting the optimal density. Figure $3 \mathrm{~b}$ shows the dimension of a mold in cylinder shape; $100 \mathrm{~mm}$ length, 40 $\mathrm{mm}$ diameter, and producing $5 \mathrm{~cm}$ high briquettes, with heating systems using the Arduino UNO programs and thermal controller. Briquette volume is determined by the formula $[2,13]$.

$$
\text { Volume }=\pi \mathrm{r}^{2} \cdot \mathrm{t}
$$

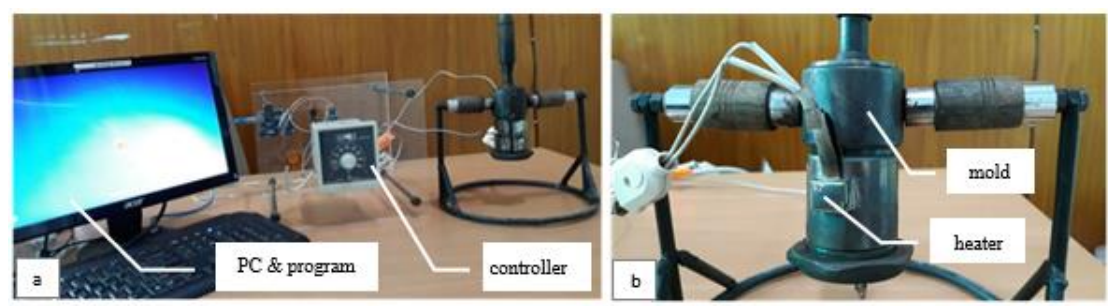

Figure 3. Heater systems using the Arduino program and thermo controller (a), and mold of briquettes with heater (b).

Bio-briquette which is mostly produced has above $1000 \mathrm{~g} / \mathrm{cm}^{3}$ density, i.e. by sinking the briquette into the water for quality testing. Lignocellulosic materials have physical upper density limit of $1500 \mathrm{~g} / \mathrm{cm}^{3}$. The process using high pressure, e.g. pellet presses, mechanical piston, or some screw extruders, made the briquettes compact with the range of density between 1200 to $1400 \mathrm{~g} / \mathrm{cm}^{3}$. Meanwhile, briquette was pressed using hydraulic piston to gain less dense bio-briquettes, i.e. under $1000 \mathrm{~kg}$. It was ineffective to produce dense briquette as the properties of combustion probably came up [14]. In this study, the density was calculated using the following (2):

$$
\rho=\mathrm{B} / \mathrm{V}
$$

where :

$\rho=$ density $\left(\mathrm{g} / \mathrm{cm}^{3}\right)$

$\mathrm{B}=$ initial mass of briquette $(\mathrm{g})$

$\mathrm{V}=$ briquette volume $\left(\mathrm{cm}^{3}\right)$.

In this case, the density was set at $0.8 \mathrm{~g} / \mathrm{cm}^{3}$ while the briquette mass (B) was set at $50.3 \mathrm{~g}$.

\section{RESULTS AND DISCUSSION}

Empty Fruit Bunches as organic material has a basic characteristic in the form of physical and chemical properties. The physical properties and chemical properties of empty fruit bunches [3] can be seen in Table 1. 
Table 1. Chemical composition of empty fruit bunches fiber

\begin{tabular}{lll}
\hline No & Chemical Components & Composition (wt\%) \\
\hline 1 & Lignin & $15-17$ \\
2 & Cellulose & $36-42$ \\
3 & Hemicellulose & $25-27$ \\
4 & Ash & $0.7-6$ \\
\hline
\end{tabular}

This research is called as biomass briquettes and is all about a conversion process of agricultural waste to be biomass briquette. The main ingredients of empty fruit bunches are lignin, cellulose, and hemicellulose. Lignin is a natural polymer that has the main function as an adhesive in plant layers. Lignin has functional groups such as hydroxyl, carbonyl and methoxy and has a low solubility to water so it has the potential to be used as an binder. Every material that contains cellulose and lignite is considered suitable for densification process. This research was mainly about converting the materials as bio-briquettes utilizing wastes of empty fruit bunches to get calorific value.

\subsection{Calorific value}

According to Table 2 Calorific Value is one of the fuel characteristics. It can be defined as the energy per $\mathrm{kg}$ it disburses when it is burnt. Therefore, it can be utilized to measure the competitiveness of fuel processed in a specific situation of the market. There are some other factors that may influence the market value such as burning characteristics and ease of handling. However, calorific value may remain becoming the most critical factor and it should be considered while choosing the input of raw materials $[12,14]$.

\begin{tabular}{ll} 
Table 2. Calorific values of the raw materials \\
\cline { 1 - 2 } Materials & Calorific Values \\
\hline Bagasse & $4380 \mathrm{k}$ \\
Sawdust briquette & $3860 \mathrm{k}$ \\
Cotton Stalks /chips & $4252 \mathrm{k}$ \\
Bamboo dust & $4160 \mathrm{k}$ \\
Coffee husk & $4045 \mathrm{k}$ \\
Tobacco waste & $2910 \mathrm{k}$ \\
Tea waste & $4237 \mathrm{k}$ \\
Paddy straw & $3469 \mathrm{k}$ \\
Mustard straw & $4200 \mathrm{k}$ \\
Wheat straw & $4300 \mathrm{k}$ \\
Sunflower stalk & $4300 \mathrm{k}$ \\
Jute waste & $4428 \mathrm{k}$ \\
Palm husk & $3900 \mathrm{k}$ \\
Soya bean husk & $4170 \mathrm{k}$ \\
Barks wood & $1270 \mathrm{k}$ \\
Forestry waste & $3000 \mathrm{k}$ \\
Coir pitch & $4146 \mathrm{k}$ \\
Rice husk & $3200 \mathrm{k}$ \\
Wood chips & $4785 \mathrm{k}$ \\
Groundnut shell & $4524 \mathrm{k}$ \\
\hline
\end{tabular}

Empty Fruit Bunches fiber moisture content greatly determines the quality of bio-briquettes produced. Bio-briquette with a low water content will produce high heat values, as it is produced from a type of fiber that has a low moisture content. In this case, the higher the water content of briquettes, the lower the calorific value is. This is because the generated heat first used to evaporate water in the fiber before producing heat that can be used as heat combustion. In other words, the water content is directly related to the heating value. The calorific value determines the quality of briquettes. The higher the heat value, better quality of the briquettes is produced. Low water content, ash content and volatile matter can increase heating values. High carbon content can increase heating values. The test of the calorific value aims to determine the extent of the value of combustion heat produced by briquettes. Densification of temperature is an important factor that could affect the combustion properties especially calorific value. When the operating temperature is relatively high, the calorific value of the densified products increases if compared to the value of the raw materials [15]. The calorific value test is shown in Figure 4. The highest calorific value was produced at a temperature of $250^{\circ} \mathrm{C}$ with a value of $5256 \mathrm{cal} / \mathrm{g}$. Meanwhile, the lowest value was produced at a temperature of $150{ }^{\circ} \mathrm{C}$ with a value of $4117.8 \mathrm{cal} / \mathrm{g}$. One of the factors is that at a temperature of $250{ }^{\circ} \mathrm{C}$, 
the briquette produces a low moisture content and high charcoal content so that the briquette produces an optimal heat value at this temperature. Based on the experimental works performed on the binderless empty fruit bunches briquettes, it can be concluded that the physical appearance of a binderless palm biomass briquette is the best when the smallest size of particles is used. This is mainly due to the increase in contact surface area when smaller size is used, thus stimulates the production of lignin, which in turn improves the effectiveness of lignin as a natural binder.

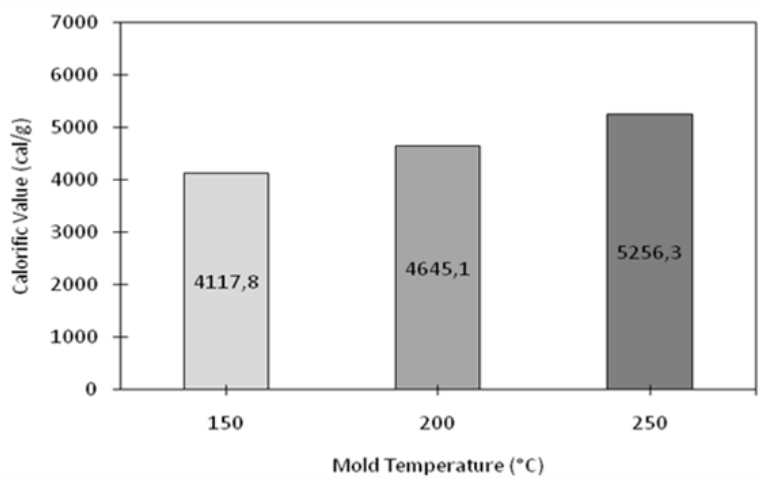

Figure 4. Graph of calorific value vs mold temperature

Figure 5 shows an analysis of water content at a mold temperature of $150{ }^{\circ} \mathrm{C}$ with a water content of $6.2 \%$. This condition is higher than the value of water content at mold temperatures of $250{ }^{\circ} \mathrm{C}$ and $200{ }^{\circ} \mathrm{C}$. Generally, this value is still below the water content standard value according to SNI 01-6235-2000 regarding the quality standards of charcoal briquettes that are equal to a maximum of $8 \%$. The water content showed different loss since the higher mold temperature given to the briquettes, the lower water content contained in the briquettes, the water content in the fiber evaporates during the molding process. The lower the water content in briquettes, the higher the heat value is produced. The cellulose content in the fiber will affect the amount of charcoal bound in the briquette. The greater cellulose content causes the greater level of charcoal bound; this is because the constituent component of cellulose is carbon [16]. The greater the carbon content of the substance bound to the raw material, the higher the calorific value is. The amount of charcoal in graph of Figure 5 produces the highest level of charcoal at a mold temperature of $250{ }^{\circ} \mathrm{C}$ with a value of $49.4 \%$. Meanwhile, the lowest level of charcoal was at a mold temperature of $150{ }^{\circ} \mathrm{C}$ with a value of $16.2 \%$. This is because the higher temperature given produces high levels of charcoal. High levels of charcoal will produce higher heat values. Ash is the remaining part of the combustion process which has no element of carbon. The main element of ash is silica; and its effect is not good on the heat value produced. In this case, the higher the ash content, the lower the quality of briquettes as the high ash content can reduce the heat value. On ash content testing, briquettes produced a high ash content of $12.2 \%$ at a mold temperature of 250 ${ }^{\circ} \mathrm{C}$, and only produced the lowest ash content of $5.7 \%$ at a temperature of $150{ }^{\circ} \mathrm{C}$. By increasing the temperature of the briquette, there is an increase in the amount of ash in the briquette. This will have an impact on the quality of briquettes, especially on calorific values.

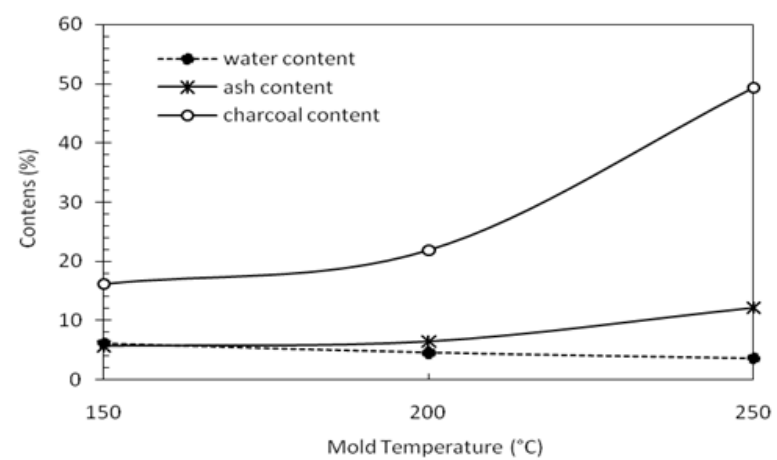

Figure 5. Graph of relation between water, ash, charcoal contents vs mold temperature 


\subsection{Bio-briquette combustion test}

One of the main variables in a bio-briquette is to obtain the maximum activation time for a combustion process so that economically the value will be beneficial for the user. Figure 6 indicates that the ignition/combustion of fire lasts longer in a bio-briquette sample at a mold temperature of $150{ }^{\circ} \mathrm{C}$ with a time of 11.3 minutes. Meanwhile, the fastest bio-briquette sample ignition of fire in mold temperature briquettes is $250{ }^{\circ} \mathrm{C}$ with a time of 6.3 minutes. The higher the heating temperature given, the bio-briquette activation time will also experience faster blackouts.

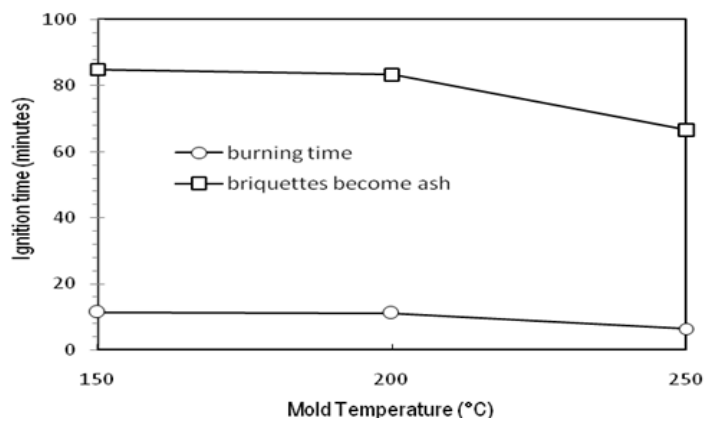

Figure 6. Graph of the relation between ignition time vs mold temperature

The results of the combustion test indicate that the bio-briquette sample is burned and takes \pm 15 to 20 seconds so that the sample emits fire until it burns completely. Bio-briquettes at mold temperatures of 250 ${ }^{\circ} \mathrm{C}$ went through faster combustion processes when compared to heating temperatures at $200{ }^{\circ} \mathrm{C}$ and $150{ }^{\circ} \mathrm{C}$. It can be indicated that at a mold temperature of $250{ }^{\circ} \mathrm{C}$ the quality of the fiber has undergone drying at such high temperatures so that the fiber is slightly charred around the outer side. Result of combustion of biobriquette samples is shown in Figure 7.

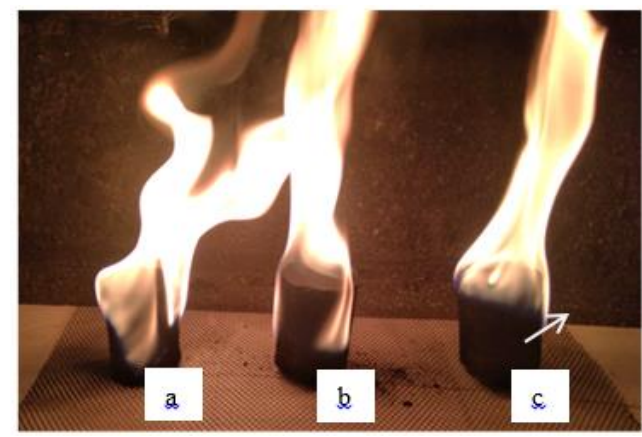

Figure 7. Burning the sample at each temperature, $150{ }^{\circ} \mathrm{C}(\mathrm{a}), 200{ }^{\circ} \mathrm{C}(\mathrm{a})$, and $250^{\circ} \mathrm{C}$ (c)

In the briquette ignition test, the resulted average fire has a good ignition and produces a large fire. Furthermore, there is also the burning of blue flame in all three samples as shown in the arrow, even though there is no significant blue flame produced. The briquette process is also highly affected by the size of fraction. In this case, it needs higher compacting power for coarser fraction of briquette. Bigger size of fraction will decrease the force of binding contained in the materials. As a result, decay process will be found faster by burning it and it is considered a disadvantage. Bigger size of fraction increases the compacting pressure and lowers the quality of briquette. On the other hand, smaller size of fraction brings an advantage in the drying process [17]. In this case, the drying process ends faster yet achieves better drying quality. Hence, the materials must be set at a suitable size of fraction and dried to a certain moisture content before conducting the briquette process [18]. 


\section{CONCLUSION}

The use of waste as an alternative energy fuel is beneficial to reduce pollution to the environment by producing bio-briquette products used by the community. The results show that the effect of using the appropriate heating temperature on bio-heating of empty fruit bunches fiber briquettes affected the resulted heating value and the toughness of bio-briquettes. The highest heating value was obtained at a mold temperature of $250{ }^{\circ} \mathrm{C}$ with a value of $5256 \mathrm{cal} / \mathrm{g}$, and the lowest one was resulted at a temperature of $150{ }^{\circ} \mathrm{C}$ at $4117 \mathrm{cal} / \mathrm{g}$. Manufacture and testing of bio-briquettes of empty fruit bunches binderless with heating methods on certain molds and tempers was capable of producing briquettes with heating values equivalent to coal briquettes.

\section{ACKNOWLEDGMENTS}

The authors would like to express their gratitude to the supervisors, Agroindustry Laboratory of Andalas University, and Laboratory of Mechanical Engineering Department of Institut Teknologi Padang (ITP).

\section{REFERENCES}

[1] Z. Helwani, et al., "Effect of process variables on the calorific value and compressive strength of the briquettes made from high moisture EFB," IOP Conf. Series: Materials Science and Engineering, vol. 345, pp. 012020, 2018.

[2] H. Nofriady, et al., "Effect of Binders on EFB Bio-briquettes of Fuel Calorific Value," IJASEIT Journal, vol. 8 no. 4, pp. 1071-1076, 2018.

[3] M. Kumar, et al., "Biomass briquette production: A propagation of non-convention technology and future of pollution free thermal energy sources," (AJER), vol. 04, pp. 44-50, 2015.

[4] H. Nofriady, et al., "Effect of particles size on EFB Bio-briquettes of calorific value," JTM. vol. 7, no. 1, pp. 56-62, 2017.

[5] P. Wilaipon, "The effects of briquetting pressure on banana-peel briquette and the banana waste in Northern Thailand," American Journal of Applied Sciences, vol. 6, no. 1, pp.167-171, 2009.

[6] H. M. Faizal, et al., "Review on densification of palm residues as a technique for biomass energy utilization," J. Teknologi. vol. 78, no. 9-2, pp. 9-18, 2016.

[7] H. Djeni, "Engineering of wood pellet making and testing results," Forest Products Research Journal, vol. 30, no. 2, pp. 144-154, 2012.

[8] R. Yuli et al., "Effect of temperature and concentration of adhesives on the characteristics of bioarang briquettes made from palm oil empty fruit bunches by pyrolysis process (in Bahasa)," Konversi, vol. 4, no. 2, pp. 16-22, 2015.

[9] F. Hasan Mohd. et al., "Characteristics of binderless palm biomass briquettes with various particle sizes," Jurnal Teknologi, vol. 77, no. 8, pp. 1-5, 2015.

[10] S. Danang et al., "Characteristics of briquettes from sengon wood processing waste by hot print method," Proceedings of the national seminar on science \& technology applications III, A-394-A400, 2012.

[11] A. B. Nasrin, et al., "Oil Palm Biomass as Potential Substitution Raw Materials for Commercial Briquettes Biomass Production,” American Journal of Applied Sciences, vol. 5, no. 3, pp. 179-183, 2008.

[12] D. Cattaneo, "Briquetting - a forgotten opportunity," Wood Energy, The University of Brescia, 2003.

[13] H. M. Faizal, et al., "Review on densification of palm residues as a technique for biomass energy utilization," J. Teknologi, vol. 78, no. 9-2, pp. 9-18, 2016.

[14] K. Basar, et al., "Frequency and temperature-dependent on conductivity from superionic conducting glass $(\mathrm{AgI})_{\mathrm{x}}\left(\mathrm{AgPO}_{3}\right)_{1-\mathrm{x}}, "$ Proceedings of the International Conference on Mathematics and Natural Science, pp. $881,2006$.

[15] A. Kurniawan, "Analysis of Combustion Characteristics of Palm Oil Industrial Waste Briquette Varying Temperature Adhesives and $300^{\circ} \mathrm{C}$ Wall Furnaces, $400^{\circ} \mathrm{C}$ and $500^{\circ} \mathrm{C}$ Heat Flux Method Using Constant (Hfc) " 2015.

[16] M. Ervando, "Effect of mold temperature variations on the characteristics of sengon wood briquettes on compression pressure of 600 psig (in Bahasa)," 2013, Online [Available]: https://lib.unnes.ac.id/17992/1/5201408077.pdf.

[17] K. Jaan, et al., "Determination of physical, mechanical and burning characteristics of polymeric waste material briquettes," Estonian Journal of Engineering, vol. 16, no. 4, pp. 307-316, 2010.

[18] C. Antwi-Boasiako and B.B. Acheaampong, "Strength properties and calorific values of sawdust-briquettes as wood-residue energy generation source from tropical hardwoods of different densities, biomass and bioenergy," vol. 85, pp. 144-152, 2016. 


\section{BIOGRAPHIES OF AUTHORS}
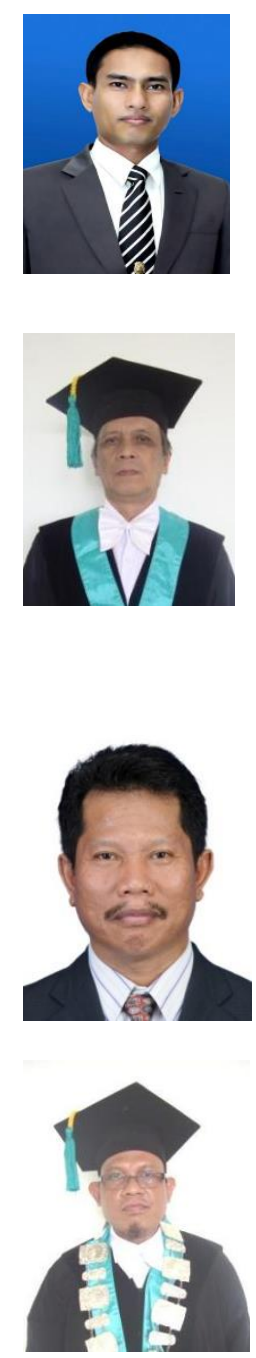

Currently, the researcher is a lecturer at the Institut Teknologi Padang (ITP) in the mechanical engineering study program. He completed his master's program at the University of Kebangsaan Malaysia in the field of mechanical and materials engineering in 2010. Currently, he is finishing his doctoral program at Universitas Andalas Padang with Empty Fruit Bunch (EFB) biomass waste processing specifications into briquette products as a source of fuel energy.

Prof. Dr. rer.nat. Anwar Kasim is a lecturer in the Faculty of Agricultural Technology at Universitas Andalas Padang Indonesia. He finished his Bachelor's degree in Agriculture Technology. He graduated with his Ph.D. in Forestry and Wood Technology in Technische Universitaet Hamburg, Germany in 1990. His recent works are about Food Technology and Engineering. He had a lot of research since 1995 about Agroforestry. He had three national Patents in Uncaria Gambier.

Prof. Dr. Eng. Gunawarman is a teaching staff in the Mechanical Engineering Department at the Andalas University Padang. 1995: Master of Engineering; Study Program of Magister Material Engineering, Graduate School of Institut Teknologi Bandung, Bandung, Indonesia 2002 and Doctor of Engineering; Toyohashi University of Technology (TUT), Toyohashi, Aichi-ken, Japan.

Prof. Dr. Santosa is a lecturer at the Agricultural Engineering Faculty of the Agricultural Technology Andalas University Padang. The field of research science is Agricultural mechanization in the machine management system regional specifications. The master's program was completed in 1993 and the doctor completed in 2002 at the Institut Pertanian Bogor. Fields of research: Agricultural Machinery Management System, Agricultural Equipment and Machinery Design, Techno-Economic Agricultural Tools and Machines, System Simulation and Computer Programming. 